\title{
Studies of Glycine Metabolism and Transport in Fibroblasts from Patients with Nonketotic Hyperglycinemia
}

\author{
DAVID M. HALTON ${ }^{(25)}$ AND INGEBORG KRIEGER \\ Wayne State University School of Medicine. The Metabolic Service, Department of Pediatrics, Children's Hospital of \\ Michigan, Detroit, Michigan, USA
}

\section{Summary}

Glycine transport in both normal and nonketotic hyperglycinemia fibroblasts was shown to occur by a sodium-dependent system. No significant difference could be detected in either the $K_{\mathrm{m}}$ 's $(1.4$ to $2.0 \mathrm{mM}$ ) or the $V_{\max }$ 's (6.2 to 16 nmole per mg protein per min) of the three control and three patient cell lines. Valine was a weak competitive inhibitor of glycine uptake. $K_{i}$ 's from both groups fell into the 5.6 to $5.8 \mathrm{mM}$ range. Plasma levels of valine of one patient reached a maximum of $0.6 \mathrm{mM}$ following a valine load. Glycine cleavage activity could not be detected in either control or nonketotic hyperglycinemia fibroblast lines. Serine utilization was the same in both nonketotic hyperglycinemia and control lines.

\section{Speculation}

The fibroblast lines of nonketotic hyperglycinemia patients used in our study indicate that a glycine transport defect is not the cause of the elevated cerebrospinal fluid glycine levels observed in nonketotic hyperglycinemia. The clinical valine effect is unlikely to be related to the inhibition of glycine transport by valine.

Nonketotic hyperglycinemia (NKH) is a metabolic disease characterized by the early onset of hypotonia, lethargy, and myoclonic convulsions. No treatment yet devised has avoided the profound mental retardation in surviving patients. A disproportionate elevation of glycine is seen in the cerebrospinal fluid and a decrease in the activity of the glycine cleavage enzyme in brain and liver $(10,12)$ has been reported. However, this abnormality has also been found in the biochemically distinct disorder, ketotic hyperglycinemia $(2,12)$ which raises the possibility that it may not be the primary genetic defect in NKH.

In some patients with $\mathrm{NKH}$, valine has been show'n to induce coma and markedly exacerbate the hypotonia $(7,8)$. This striking effect has led to the suggestion that NKH represents a defect in valine metabolism (8)

More recently, Revsin and Morrow (11) found $V_{\max }$ differences in fibroblast glycine transport between NKH and control cell lines. An inhibition of glycine transport by valine was briefly noted by these authors.

In our study, we investigated the influence of valine on glycine transport as a possible cause of the clinical valine effect. Glycine oxidation and serine utilization in fibroblasts were also examined.

\section{MATERIALS AND METHODS}

Human diploid fibroblasts (24) from three normal and three NKH patients were grown in Eagle's minimal essential medium (13) containing $10 \%$ fetal calf serum, penicillin $(100 \mathrm{U} / \mathrm{ml})$, and streptomycin $(100 \mu \mathrm{g} / \mathrm{ml})$.

For transport studies, cells were grown on washed sterile coverslips $(11 \times 22 \mathrm{~mm})(14)$. With the fibroblasts at confluency, the coverslips were rinsed twice with phosphate-buffered saline glucose (PBSG) [130 mM NaCl, $5 \mathrm{mM} \mathrm{KCl}, 1.2 \mathrm{mM} \mathrm{MgSO}_{4}, 1 \mathrm{mM}$ $\mathrm{CaCl}_{2}, 5 \mathrm{mM}$ glucose, and $\left.10 \mathrm{mM} \mathrm{Na}_{2} \mathrm{HPO}_{4}(\mathrm{pH} 7.4)\right]$. In a final wash, the coverslips were left for one hr in PBSG at $37^{\circ} \mathrm{C}$ to minimize endogenous glycine levels.

The incubation procedure was similar to that of Foster and Pardee (3). Four $\mu \mathrm{l}$ of $\left[2-{ }^{14} \mathrm{C}\right] \mathrm{glycine}(15)$ were added per $\mathrm{ml}$ of incubation medium containing PBSG, unlabeled glycine, and, in some studies, valine. Incubations were carried out for $2 \mathrm{~min}$ at $37^{\circ} \mathrm{C}$. After incubation, coverslips were rinsed in three separate solutions of PBSG (total rinse time, approximately $5 \mathrm{sec}$ ). Drained coverslips were then placed in a scintillation cocktail, TEG (16), and left for one hr before counting. Protein was determined by a modification of the method of Lowry et al. (9).

For studies of the metabolism of glycine and serine, fibroblasts were grown in Falcon flasks (17), under the same conditions as the cells grown for transport studies. At confluency, cells were harvested with $0.25 \%$ trypsin and washed three times in isotonic saline. After the final spin (1000 rpm; Sorval RC-3) cells from each flask were resuspended in $1 \mathrm{ml}$ of PBSG and disrupted by sonic vibration (18). An incubation medium was prepared containing $1.5 \mathrm{mM} \mathrm{NAD}{ }^{+}, 1 \mathrm{mM}$ dithiothreitol, $0.5 \mathrm{mM}$ pyridoxal phosphate, and $1 \%(w / v)$ bovine serum albumin made up with PBSG (19). Ten $\mu$ l of either $\left[1-{ }^{14} \mathrm{C}\right]$ glycine $(54 \mathrm{mCi} / \mathrm{mole})(20)$ or DL- $\left[1-{ }^{14} \mathrm{C}\right]$ serine $(51 \mathrm{mCl} / \mathrm{mole})(20)$ were added to $4 \mathrm{ml}$ of the incubation medium. To a series of tubes each containing $2 \mu \mathrm{l}$ of $1 \mathrm{mM}$ tetrahydrofolic acid in $0.2 \mathrm{mM}$ mercaptoethanol, $0.1 \mathrm{ml}$ of disrupted fibroblasts $(0.2$ to $0.5 \mathrm{mg}$ protein) and $0.2 \mathrm{ml}$ of incubation medium were added. Kontes center wells (21) containing $0.3 \mathrm{ml}$ of soluene (22) were suspended from rubber caps that sealed the incubation tubes. Incubations were carried out at $37^{\circ} \mathrm{C}$ with gentle shaking for one hr. Tubes were then placed on ice, and the contents of each well was counted in Toluene-Liquifluor (23).

\section{RESULTS}

\section{TRANSPORT STUDIES}

The time course uptake of 1 and $2 \mathrm{mM}$ glycine was linear for at least $20 \mathrm{~min}$ (Fig. 1). The use of $\left[2-{ }^{14} \mathrm{C}\right]$ glycine in this study precluded the possibility of label loss by glycine oxidation subsequent to transport. No signficant difference in uptake pattern could be observed between NKH and control cell lines. Uptake in the absence of sodium or in the present of $10^{-3} \mathrm{M}$ oubain was minimal and presumably reflects entrance of glycine by simple diffusion (Fig. 1).

$\mathrm{V}_{\max }$ 's for NKH cell lines were 6.2 to 16.6 nmoles per mg protein per min, and for controls, they were 6.0 to 10.0 nmoles per $\mathrm{mg}$ protein per min. Corresponding $\mathrm{K}_{\mathrm{m}}$ 's were 1.4 to $2.0 \mathrm{mM}$ and 1.6 to $2.0 \mathrm{mM}$ (Fig. 2). Valine was a weak competitive inhibitor of both $\mathrm{NKH}$ and control cell lines with $\mathrm{K}_{\mathrm{i}}$ 's for both groups in the 5.6 to $5.8 \mathrm{mM}$ range (Table 1; Figs. 3 and 4 ). 


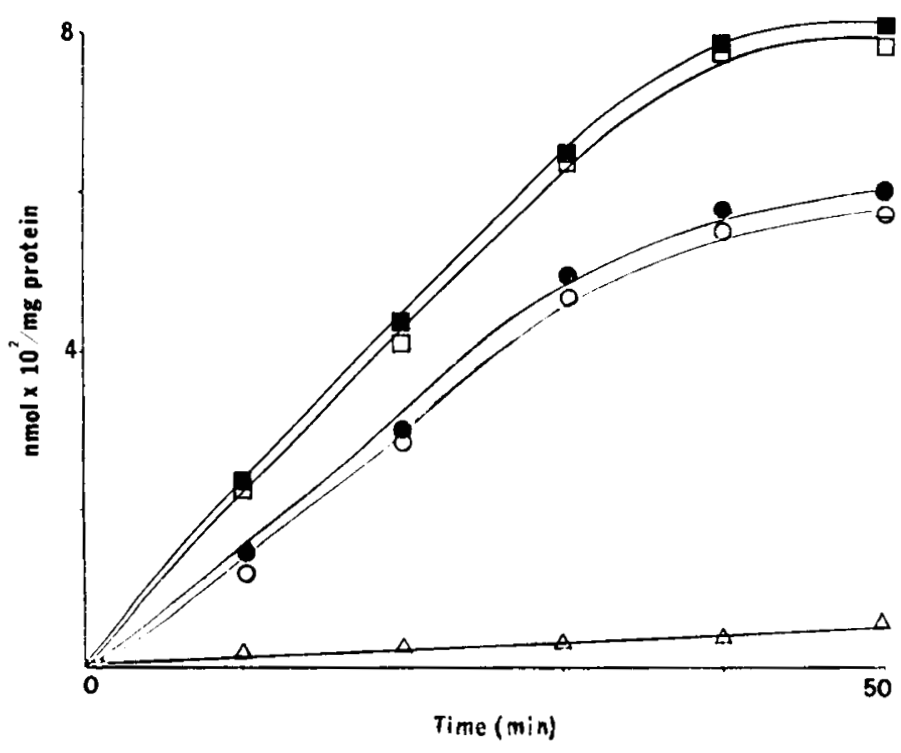

Fig. 1. The uptake of $1 \mathrm{mM}(\mathrm{O}, \bullet)$ and $2 \mathrm{mM}(\square, \square)$ glycine by fibroblasts. $\square$ mean of three NKH cell lines. $O, \square, \triangle$, mean of three control cell lines. $\Delta$, represents the uptake of glycine in the absence of sodium or in the presence of $10^{-3} \mathrm{M}$ oubain. Tris and choline were substituted for sodium in the sodium dependency experiment. Points, mean of three determinations on three different NKH or control cell lines. i.e., a total of nine determinations for each point.

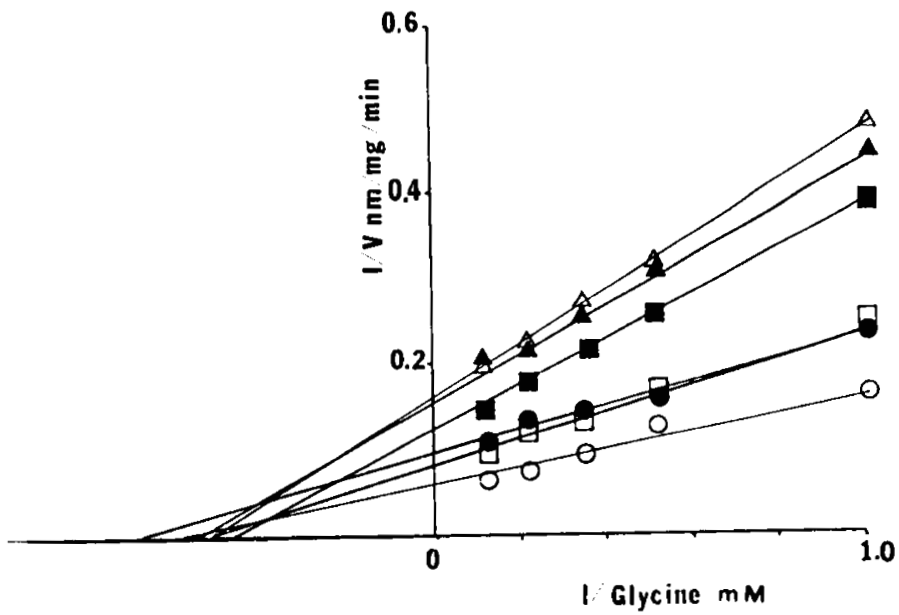

Fig. 2. A double reciprocal plot for glycine transport. $\bullet, \mathbf{\square}, \mathbf{\Delta}, \mathrm{NKH}$ lines: $O, \square, \Delta$, controls. Incubations were for $2 \mathrm{~min}$.

Table 1. Comparison of $K_{i}$ 's for valine inhibition of three control and three $N K H$ cell lines

\begin{tabular}{lccc} 
& \multicolumn{3}{c}{$\mathrm{K}$ 's $(\mathrm{mM})$} \\
& 1 & 2 & 3 \\
\hline Control cell lines & 5.4 & 5.8 & 5.5 \\
NKH cell lines & 5.6 & 5.7 & 5.4 \\
\hline
\end{tabular}

\section{GLYCINE METABOLISM}

In the incubation studies using labeled glycine, no distinction could be made between nonenzymatic ${ }^{14} \mathrm{CO}_{2}$ production and that formed in the presence of either disrupted or whole fibroblasts. $\mathrm{CO}_{2}$ release did not significantly lower the $\mathrm{pH}$ of the incubation medium. The removal of each component, in turn, from the incubation medium did not alter this result and increasing the incubation time up to $6 \mathrm{hr}$ was without effect. Glycine oxidation

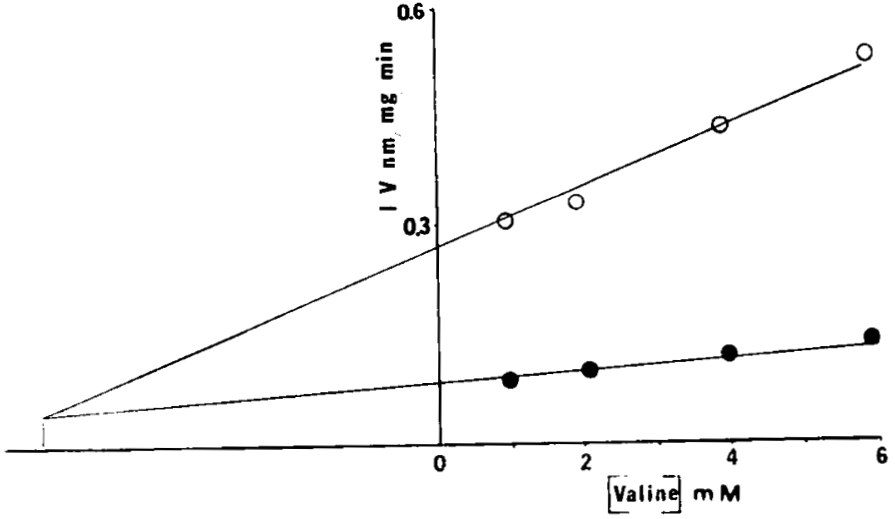

Fig. 3. Dixon plot for valine inhibition of glycine t1 ansport in a valinesensitive NKH cell line. Incubation times were $2 \mathrm{~min}$. O, $1 \mathrm{mM}$ glycine, . $5 \mathrm{mM}$ glycine.

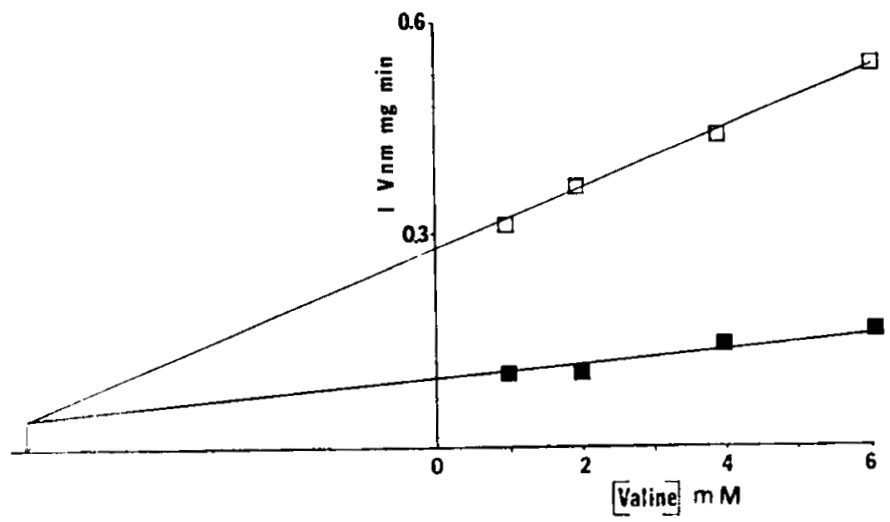

Fig. 4. Dixon plot of a control cell line. Incubation times were for 2 min. $\square, 1 \mathrm{mM}$ glycine, $15 \mathrm{mM}$ glycine.

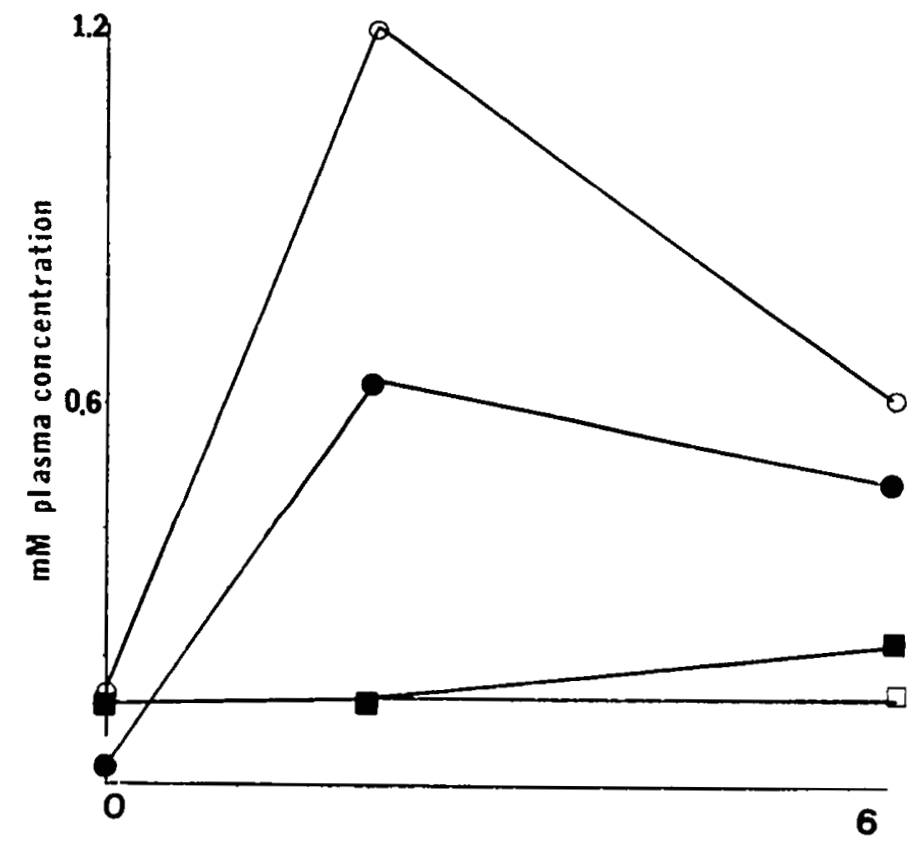

Fig. 5. Glycine and valine plasma levels during valine loading. $O$, control valine; $\bullet$, NKH valine; $\square$. control glycine; $\boldsymbol{Q}$, NKH glycine (see Ref. 7). 
in fibroblasts was not detected by this method. A total of 48 incubations were carried out in this study.

\section{SERINE METABOLISM}

Similar incubation studies with $\mathrm{DL}-\left[1-{ }^{14} \mathrm{C}\right]$ serine produced a different result. In this instance, the ${ }^{14} \mathrm{CO}_{2}$ released in the presence of disrupted cells was only 50 to $60 \%$ of that observed in controls showing nonenzymatic $\mathrm{CO}_{2}$ production. This reduction in ${ }^{14} \mathrm{CO}_{2}$ release was the same for both $\mathrm{NKH}$ and control cell lines. This result was obtained eight times.

\section{DISCUSSION}

The $\mathrm{K}_{\mathrm{m}}$ 's for glycine transport in the controls and NKH cell lines for laboratory (1.4 to $2.0 \mathrm{mM}$ ) are comparable with those obtained elsewhere ( 1.1 to 2.4 and 0.65 to $4.2 \mathrm{mM})(5,12)$. Kelly et al. (5) noted slightly lower $K_{m}$ 's for normal cell lines than NKH lines.

In our studies, $V_{\max }$ 's could not be used to distinguish control from NKH cells. Revsin and Morrow (12) found higher $V_{\max }$ 's for control cell lines than those reported here or those noted by Kelly et al. (5). $\mathrm{V}_{\max }$ 's for $\mathrm{NKH}$ cell lines are comparable in all three studies. Kelly et al. (5) claim difficulty in comparing their data to that of Revsin and Morrow (12) because the latter authors used 20-min incubation times while the former incubated for only one min. However, this point is equivocal because the rate is the same for at least $20 \mathrm{~min}$ if the uptake is linear as it was in this study.

The pathogenesis of the coma following valine loading is unknown. It appeared possible that this amino acid inhibits glycine transport in NKH more than in controls. However, there was no significant difference in the $K_{i}$ 's for valine inhibition of glycine transport in fibroblasts. Plasma valine levels in the valine loaded NKH patient did not exceed $0.6 \mathrm{mM}$ (Fig. 5), which is less than one-eight of the concentration required to effect a half saturation of the glycine transport system. Assuming that the findings in fibroblasts reflect transport in the central nervous system, these data do not suggest that the clinical valine effect is related to inhibition of glycine transport by valine.

Demonstration of an abnormality in the glycine cleavage system by use of skin fibroblasts would be most useful in the diagnosis of NKH and would avoid the necessity of in vivo radiochemical studies (1). However, there are conflicting reports in this area. Hillman et al. have demonstrated a ${ }^{14} \mathrm{CO}_{2}$ release from $\left[U-{ }^{14} \mathrm{C}\right]$ glycine incubated with fibroblasts. $\mathrm{A}$ much greater ${ }^{14} \mathrm{CO}_{2}$ release was reported when cells were grown in F10 medium rather than Eagle's medium which has a higher isoleucine content (4). In more recent studies Kolvraa (6) could not observe a significant ${ }^{14} \mathrm{CO}_{2}$ release from fibroblasts grown on either F10 or Eagle's medium. We also could not show any ${ }^{14} \mathrm{CO}_{2}$ release from the fibroblasts in our studies.

The reduction of ${ }^{14} \mathrm{CO}_{2}$ release from $\mathrm{DL}-\left[1-{ }^{14} \mathrm{C}\right]$ serine in the presence of cell sonicates presumably represents the ultization of $\mathrm{L}$-serine by pathways that do not immediately release $\mathrm{CO}_{2}$. The reduction was the same in both NKH and control lines and indicates that there is probably no defect in pathways of serine metabolism in this disease.

\section{REFERENCES AND NOTES}

I. Ando, T., Klingberg, W. G., Ward, A. N., Rasmussen, K. R., and Nyhan, W. L.: Metabolism of glycine in the nonketotic form of hyperglycinemia. Pediatr. Res., 2: 254 (1968).

2. Ando, T., Nyhan, W. L., Conner, J. D., Rasmussen, K., Donnell, G., Barnes, N., Cottom, D., and Hull, D.: The oxidation of glycine and propionic acid in propionic acidemia with ketotic hyperglycinemia. Pediatr. Res., 6: 576 (1973).

3. Foster, D. O., and Pardee, A. B.: Transport of amino acids by confluent and nonconfluent $3 T 3$ and polyoma virus-transformed $3 \mathrm{~T} 3$ cells growing on glass coverslips. J. Biol. Chem., 244: 2675 (1969).

4. Hillman, R. E., Sowers, L. H., and Cohen, J. L.: Inhibition of glycine oxidation in cultured fibroblasts by isoleucine. Pediatr. Res., 7: 945 (1973).

5. Kelly. J. C., Otto, E. F., and Hillman, R. E.: Glycine transport by human diploid fibroblasts-absence of a defect in cells from patients with non-ketotic hyperglycemia. Pediatr. Res., 13: 127 (1979).

6. Kolvraa, S.: Inhibition of the glycine cleavage system by branched chain amino acid metabolites. Pediatr. Res., 13: 889 (1979).

7. Krieger, I., and Hart, Z. H.: Valine sensitive non-ketotic hyperglycinemia. J. Pediatr. 85: 43 (1974).

8. Levy, H. L., Nishimura, R. N., Erickson, A. M., and Janowska, S. E.: Hyperglycinemia: in vivo comparison of non-ketotic and ketotic (proprionic acidemic) forms. 11. Valine response in non-ketotic hyperglycinemia. Pediatr. Res., 6 : $395 / 135$ (1972).

9. Lowry, O. H., Rosebrough, N. J., Farr, A. L., and Randal, R. J.: Protein measurement with the Folin phenol reagent. J. Biol. Chem., 193: 265 (1951).

10. Perry, T. L., Urquart, N., Maclean, J., Evans, M. E., Hansen, S., Davidson. A. G. F., Appeigarth, D. A., Macleod, P. J., and Lock, J. E.: Non-ketotic hyperglycinemia. Glycine accumulation due to absence of glycine cleavage in the brain. N. Engl. J. Med., 292: 1269 (1975).

11. Revsin, B., and Morrow, G., III. Glycine transport in normal and non-ketotic hyperglycinemic human diploid fibroblasts. Exp. Cell Res., 100: 95 (1976).

12. Tada. K.. Corbeel, L. M., and Eeckels. R., and Eggermont, E.: A block in glycine cleavage reaction as a common mechanism in ketotic and nonketotic hyperglycinemia. Pediatr. Res., 8: 721 (1974).

13. Grand Island Biological Co., Chagrin Falls, $\mathrm{OH}$.

14. Arthur H. Thomas Co., Philadelphia, PA.

15. Specific activity, $47.34 \mathrm{mCi} / \mathrm{mole}$; New England Nuclear, Boston, MA

16. Toluene-ethyleneglycolmonomethylether $(42 \mathrm{ml}$ of liquiflour (Ref. 23$)$ are added to one liter of scintillation toluene. Ten parts of this solution are added to six parts of ethyleneglycolomonomethlether (Fisher Scientific Co.).

17. Becton-Dickenson Co., Oxnard, CA

18. Branson model S-75 with small volume probe.; Branson Instruments Inc., Dan bury, $\mathrm{CT}$.

19. Unless otherwise stated all chemicals were obtained from Sigma Chemical Co., St. Louis, MO.

20. Research Products International Corp., Elk Grove Village, IL.

21. Kontes Glass Co.. Vineland, NJ.

22. Packard Instruments Co., Downers Grove, IL.

23. New England Nuclear, Boston, MA.

24. Informed consent was obtained from the parents for skin biopsy and enzyme studies.

25. Requests for reprints should be addressed to: Dr. D. M. Hatton, Wayne State University School of Medicine. The Metabolic Service, Department of Pediatrics, Children's Hospital of Michigan, Detroit, MI 48201 (USA).

26. Received for publication October 22, 1979.

27. Accepted for publication December 13, 1979 